\title{
Leiomiossarcoma gástrico associado a hérnia de hiato em cão da raça Shar-pei: relato de caso
}

\author{
[Gastric leiomyosarcoma associated with hiatal hernia in a Shar-pei: a case report] \\ L.O.C. Prado ${ }^{1}$, G.G. Franco ${ }^{1}$, E. Legatti ${ }^{1}$, J.J.T. Ranzani ${ }^{1}$, J.G. Quitzan ${ }^{1}$, E.G.M. Siqueira ${ }^{1}$, \\ J.A.L. Souza ${ }^{1}$, B.W. Minto ${ }^{2}$, C.V.S. Brandão ${ }^{1 *}$ \\ ${ }^{1}$ Universidade Estadual Paulista Júlio de Mesquita Filho- Unesp - Botucatu, SP \\ ${ }^{2}$ Universidade Estadual Paulista Júlio de Mesquita Filho - Unesp - Jaboticabal, SP
}

\begin{abstract}
RESUMO
Os tumores do sistema digestório não são comuns na medicina veterinária e as neoplasias de estômago representam menos de $1 \%$ de todos os tumores malignos. O leiomiossarcoma é o segundo tumor que mais acomete o trato gastrointestinal de cães, com predisposição para as regiões de jejuno e ceco, mas qualquer porção pode ser afetada, desde o esôfago até o reto. O presente trabalho relata um caso em um canino da raça Shar-pei, macho, com 13 anos de idade e histórico de episódios eméticos pós- prandiais e emagrecimento progressivo havia oito meses. Após avaliação radiográfica e endoscópica, foi indicada intervenção cirúrgica e observada tumoração gástrica associada a hérnia de hiato. $O$ diagnóstico de leiomiossarcoma gástrico foi estabelecido por meio de análise histopatológica. O paciente apresentou pouco tempo de sobrevida, entretanto destaca-se a raridade desse tipo de neoplasia gástrica e da associação desse tipo tumoral com hérnias de hiato, assim como a importância da análise histopatológica para o correto diagnóstico desse tipo de patologia.
\end{abstract}

Palavras-chave: cirurgia, estômago, oncologia, tumor

\begin{abstract}
Gastrointestinal system tumors are not common in Veterinary Medicine and stomach neoplasia represents less than 1\% of all malignant tumors. Among digestive neoplasias, the leiomyosarcoma is the second most common with predisposition to the regions of the jejunum and cecum, but any portion from the esophagus to rectum can be potentially affected. This is a case report of a 13-year-old male Shar-pei dog with medical history of post prandial emetic episodes and progressive weight loss lasting eight months. Surgical intervention was indicated after radiographs and endoscopic evaluation, where a gastric mass and hiatal hernia were found. The diagnosis of gastric leiomyosarcoma was established only after histopathological analysis. Despite the patient having little survival time, this clinical presentation of a gastric tumor associated with hiatal hernia is rare, and exalts the importance of histopathological studies as a tool for the correct diagnosis in these unusual diseases.
\end{abstract}

Keywords: oncology, stomach, surgery, tumor

\section{INTRODUÇÃO}

Na medicina veterinária, os tumores do sistema digestório não são de ocorrência comum e as neoplasias de estômago representam menos de $1 \%$ de todos os tumores malignos. Entretanto, na espécie humana, esse tipo de tumor é muito

Recebido em 29 de novembro de 2015

Aceito em 9 de junho de 2016

*Autor para correspondência (corresponding author)

E-mail: valeriasb@fmvz.unesp.br comum, sendo considerado a segunda causa de morte relacionada ao câncer. Em cães, as neoplasias de origem epitelial são as que mais comumente afetam o estômago, sendo representadas em 60 a $70 \%$ pelo adenocarcinoma, porém outros tipos, como o leiomioma e o leiomiossarcoma, podem ocorrer. Estes são provenientes da camada muscular 
interna e produzem formações em placa ou projetam-se como nódulos, geralmente sem ulceração superficial (Sobral et al., 2008).

O leiomiossarcoma é o segundo tumor que mais acomete o trato gastrointestinal de cães, com predisposição para as regiões de jejuno e ceco, mas qualquer porção pode ser afetada, desde o esôfago até o reto. Os sinais clínicos mais comuns são inapetência, perda de peso, êmese, diarreia, poliúria, polidipsia, anemia e hipoglicemia, porém podem ser inespecíficos, variando de acordo com o sítio primário ou sítios metastáticos. Cães idosos são mais comumente acometidos, entretanto não há predisposição de raça e sexo, ao contrário dos leiomiomas, que acometem com maior frequência os machos (Cohen et al., 2003).

Leiomiossarcomas são tumores malignos com potencial metastático moderado, dependendo do sítio primário, sendo pulmões e fígado os focos comuns de metástase, devido à propensão dessa neoplasia em se disseminar por via hematôgena (Frost et al., 2003; Serrano e George, 2013). Esta é uma neoplasia mesenquimal maligna, composta por linhagens celulares de músculo liso de características distintas. O padrão histológico típico do leiomiossarcoma é de interseção, independentemente da origem tumoral, apresentando células fusiformes com fascículos nitidamente marginados, citoplasma abundantemente eosinofílico e núcleos alongados e hipercromáticos. Grandes leiomiossarcomas contêm frequentemente áreas de necrose tecidual; pleomorfismo focal é comum, porém, em alguns casos, apresenta-se em maior extensão, assemelhando-se a qualquer sarcoma indiferenciado de tecidos moles (Chen et al., 2011). A análise histopatológica ou imunohistoquímica é indispensável para a realização do diagnóstico, no entanto o auxílio com imagens de ressonância magnética, para neoplasias de tecidos moles, e de tomografia computadorizada contrastada para casos de lesões retroperitoniais pode ser de grande utilidade para determinação das dimensões do real acometimento do animal pelo tumor (Serrano e George, 2013).

A ressecção cirúrgica é a escolha mais comum para o tratamento de leiomiossarcomas (Miettinen et al., 2001). Hamai et al. (2012) concluíram que a associação da remoção cirúrgica e de quimioterapia foi eficaz no controle da progressão tumoral, com aumento de sobrevida em uma paciente humana, do sexo feminino, de 66 anos de idade, diagnosticada com tumor gástrico associado a múltiplas metástases hepáticas. $\mathrm{O}$ uso da radioterapia em sarcomas de tecidos moles demonstrou controle e manutenção da função das estruturas afetadas, com diminuição da recidiva local, porém não foi representativa no aumento da sobrevida de pacientes humanos. Entretanto, esta terapia é considerada como padrão no pré ou pósoperatório de leiomiossarcomas de grau intermediário ou de alto grau, localizados em membros ou região de tronco, todavia não há um consenso a respeito de seus efeitos em sarcomas localizados em região retroperitoneal (Demetri et al., 2010; McBride et al., 2013).

De acordo com o sistema de estadiamento tumoral de sarcomas de tecidos moles pela AJCC (American Joint Committee on Cancer), a graduação histológica, o tamanho e a profundidade tumoral são os três fatores clínicopatológicos mais importantes para se estabelecer o prognóstico do paciente acometido, entretanto a localização anatômica da neoplasia tem sido relatada como importante fator prognóstico (Pisters et al., 1996). Anaya et al. (2008) relataram que $\mathrm{o}$ fator prognóstico mais importante para o aumento de sobrevida do paciente é a completa remoção cirúrgica, com margens de segurança microscopicamente livres do tumor.

O objetivo do presente relato é descrever as características anatomopatológicas de um caso de leiomiossarcoma gástrico associado a hérnia de hiato, em um canino da raça Shar-pei.

\section{CASUÍSTICA}

Foi atendido um canino da raça Shar-pei, macho, 13 anos, pesando $23 \mathrm{~kg}$. Durante a anamnese, foram relatados episódios eméticos pós-prandiais havia oito meses e um episódio de hematemese no dia anterior à consulta. Adicionalmente foi relatada tosse noturna havia duas semanas, hiporexia e polidipsia havia uma semana, aquesia havia três dias e emagrecimento progressivo desde o início do quadro. Ao exame físico, notou-se um quadro de leve desidratação, aumento de linfonodos submandibulares e poplíteos e leve crepitação à auscultação pulmonar. O cão não apresentava sensibilidade 
dolorosa ou massa palpável em região abdominal.

Imagens radiográficas do esôfago cervical e do tórax, com suspeitas iniciais de megaesôfago adquirido, hérnia de hiato e pneumonia aspirativa, foram adquiridas. $\mathrm{O}$ laudo radiográfico revelou duas linhas radiopacas paralelas entre si na região topográfica do esôfago torácico com desvio ventral em sua porção caudal à base cardíaca, sugerindo dilatação esofágica; abaulamento de tecidos moles em região topográfica de mediastino caudal; hilo esofágico sugerindo afecções como hérnia de hiato, intussuscepção gastroesofágica e uma neoformação a esclarecer. $\mathrm{O}$ esofagograma revelou dilatação do lúmen esofágico, apresentando até $4,0 \mathrm{~cm}$ de diâmetro, com irregularidade do trajeto em sua porção torácica caudal, área linear com conteúdo contrastado sobrepondo o abaulamento em mediastino caudal, não havendo preenchimento por contraste nessa região. Por meio da nova imagem realizada após 15 minutos, observou-se conteúdo contrastado no interior do esôfago e na porção cranial do intestino delgado, sugerindo, assim, a necessidade de um exame de endoscopia e/ou tomografia computadorizada para melhor avaliação.

Ao exame endoscópico, observou-se região de hipofaringe com estruturas e coloração preservadas. $\mathrm{O}$ esôfago apresentava ausência de peristalse, eixo e calibre normais em região cranial, porém dilatado e flácido nas porções média e caudal, com discreta quantidade de resíduo alimentar, porém apresentando intensa quantidade de secreção espumosa, esbranquiçada e espessa, o que exigiu abundante lavagem da mucosa para adequada realização do exame. $\mathrm{Na}$ região entre o quinto e sexto espaço intercostal, aproximadamente, constatou-se a presença de flacidez esofágica, com oclusão do lúmen, que foi desfeita por meio de insuflação de ar pelo endoscópio e oclusão manual externa de esôfago cervical. Na região do cárdia, foi visualizada uma estrutura volumosa protruída em direção ao lúmen com intensa vascularização sanguínea superficial, impedindo a visualização e a transposição do esfíncter esofágico inferior, o que impossibilitou a avaliação das demais porções estomacais e do duodeno. Após constatação da presença dessa massa anômala e obstrução do trato digestório, foi indicada a realização do procedimento de celiotomia exploratória.

Precedendo o ato cirúrgico, o animal foi mantido em jejum alimentar de 12 horas e jejum hídrico de duas horas. Imediatamente antes do procedimento, foi administrado como antibiótico profilático ceftriaxona (Triaxon, Teuto/Pfizer, Brasil), na dose de $30 \mathrm{mg} / \mathrm{kg}$, por via intravenosa. Para indução anestésica, foi utilizado propofol (Propovan, Cristália, Brasil), na dose de $5 \mathrm{mg} / \mathrm{kg}$, por via intravenosa, e a manutenção com isoflurano (Isoforine, Cristália, Brasil) diluído em oxigênio. Após o acesso e a completa inspeção da cavidade abdominal, foi identificada uma hérnia de hiato deslizante e a presença de massa multilobada, friável, de aproximadamente $15 \mathrm{~cm}$ de diâmetro desde o fundo estomacal e estendendo-se através do hiato esofágico até a região de cárdia, presente na cavidade torácica. A presença do tumor no tórax impediu a redução do conteúdo herniado para o abdômen, o que impôs o acesso à cavidade torácica por meio de uma incisão de alargamento do hiato esofágico.

Com a redução da hérnia hiatal, foi possível a visualização completa da massa, a qual se encontrava em região extramural de fundo e cárdia (Fig. 1 e 2). Após dissecção cuidadosa do tumor, este foi, macroscopicamente, removido por completo, prosseguindo-se à realização de esofagopexia e gastropexia, assim como à correção da abertura diafragmática.

$\mathrm{O}$ animal foi mantido com sonda esofágica no período pós-operatório, porém evoluiu ao óbito aproximadamente 24 horas após a cirurgia. A massa removida foi enviada para análise histopatológica, cujo exame concluiu o diagnóstico de leiomiossarcoma gástrico. 


\section{Prado et al.}

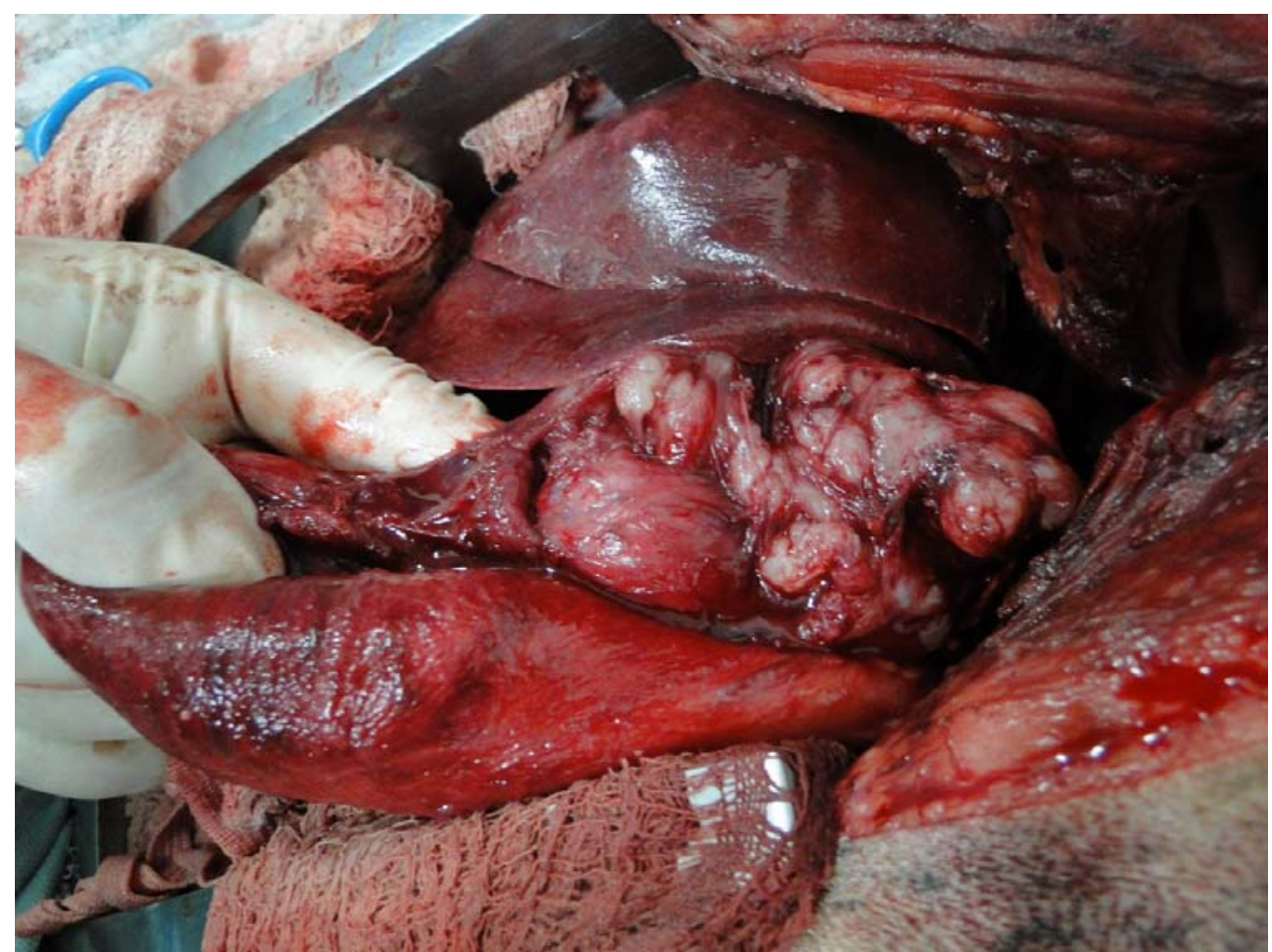

Figura 1. Procedimento cirúrgico: massa tumoral multilobada, em região extramural de cárdia e fundo estomacal, visualizada após redução de hérnia hiatal por incisão de alargamento do hiato esofágico e tração manual do corpo gástrico.

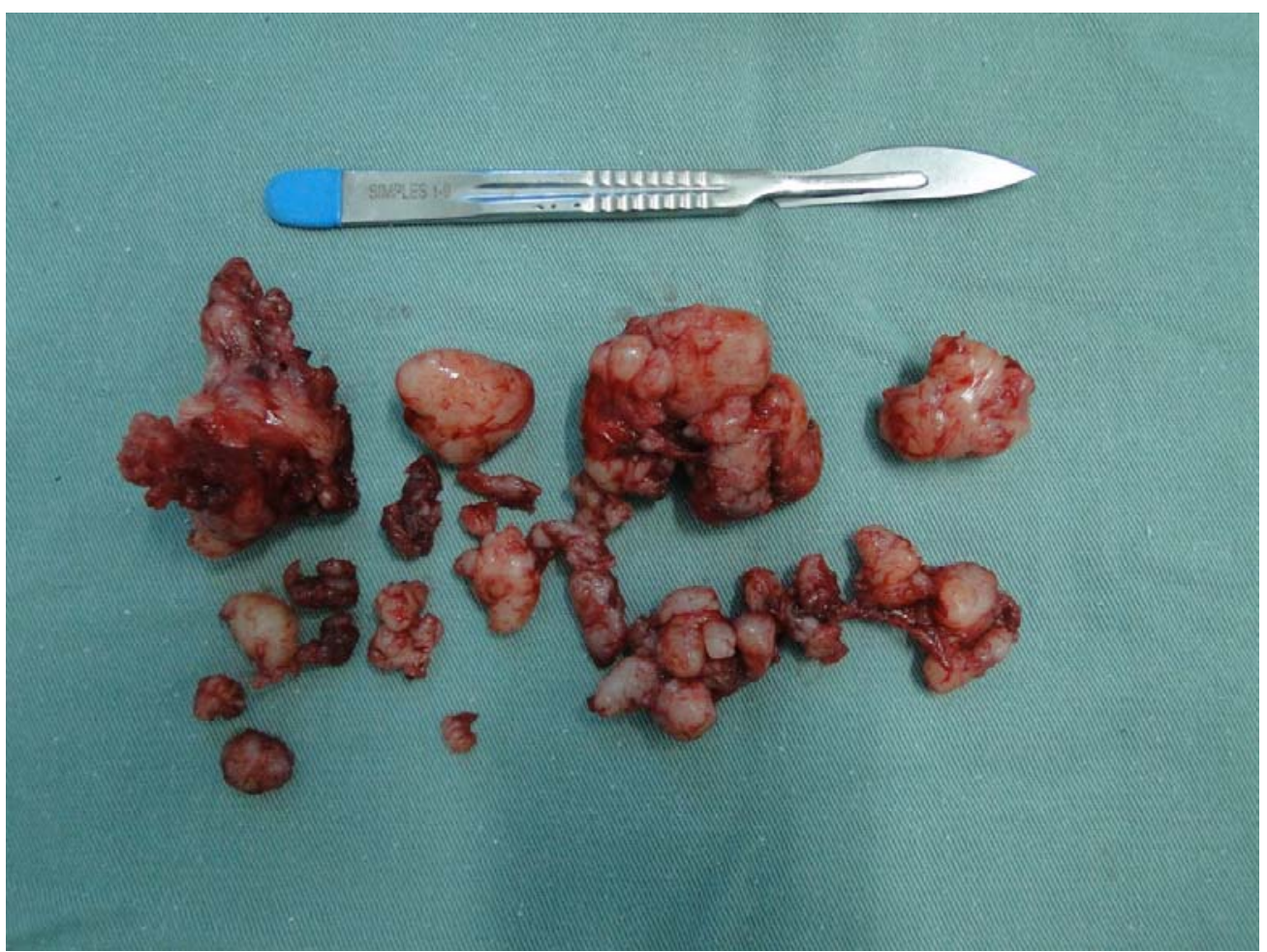

Figura 2. Peça cirúrgica: múltiplos fragmentos tumorais, de aspecto grosseiro e consistência friável, após completa remoção macroscópica. 


\section{DISCUSSÃO}

No presente relato, os exames complementares de radiografia simples e endoscopia foram de grande utilidade para a realização do diagnóstico, entretanto o diagnóstico definitivo de leiomiossarcoma gástrico teve que ser confirmado por meio de análise histopatológica (Fig. 3), a qual revelou proliferação de células fusiformes, formando arranjos em feixes multidirecionais, sustentadas por um estroma moderadamente colagenoso, destacando-se áreas focais vacuolizadas, sustentadas por uma matriz frouxa. As células apresentavam-se com citoplasma eosinofílico, de bordos indistintos, núcleo ovalado a alongado, cromatina finamente agregada, núcleo central proeminente e anisocariose acentuada. Destaca-se, ainda, a presença de acentuados corpúsculos apoptóticos e sete figuras mitóticas em 10 campos de maior aumento (40x), características semelhantes a essas já relatadas por Chen et al. (2011).

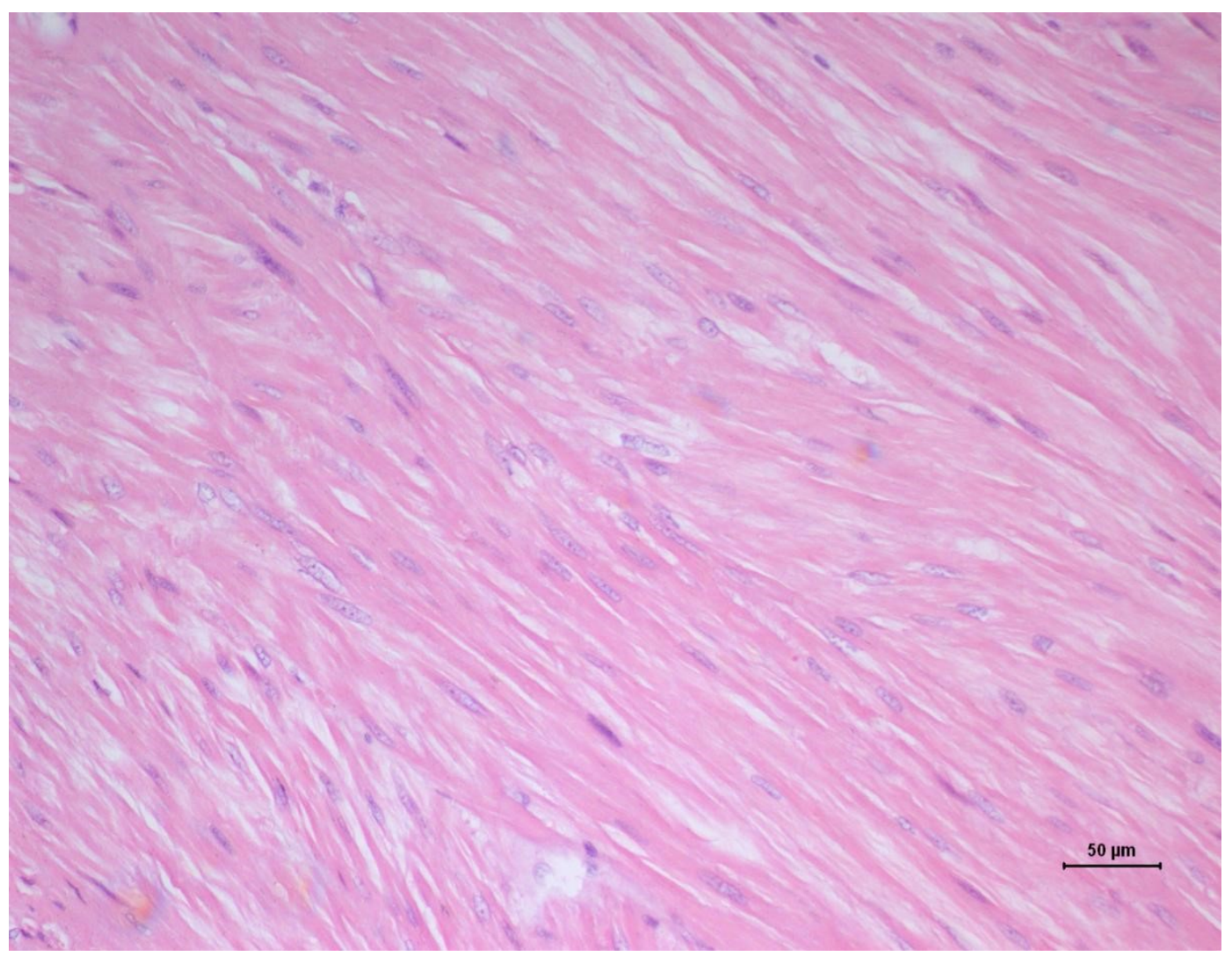

Figura 3. Leiomiossarcoma gástrico: histopatologia de massa tumoral, com presença de feixes multidirecionais de células fusiformes, com núcleo central alongado, cromatina grosseira, nucléolo único central proeminente, anisocariose acentuada, sustentadas por um denso estroma conectivo. Aumento de 20x.

O exame endoscópico foi determinante para a decisão da conduta médica realizada. A visualização de uma estrutura volumosa na região do cárdia impedindo a transposição do esfíncter esofágico inferior confirmou a necessidade de intervenção cirúrgica. A hipótese diagnóstica do exame de endoscopia foi de leiomioma gástrico, devido à maior incidência em regiões estomacais, ao contrário do leiomiossarcoma, que é visto com mais frequência em regiões de jejuno e ceco, assim como relatado por Cohen et al. (2003).

Relatos de neoplasias gástricas associados a hérnia de hiato são pouco descritos na literatura veterinária. Su et al. (2013) relataram um caso de torção gástrica organoaxial em paciente humano do sexo feminino de 72 anos, devido ao 
encarceramento de um tumor estromal gastrointestinal de origem gástrica em uma hérnia de hiato paraesofágica, porém, na medicina veterinária, esse tipo de associação é pouco (ou nada) relatado.

Embora no presente trabalho o animal tenha sobrevivido por pouco tempo no período pósoperatório, a remoção macroscópica do tumor foi considerada satisfatória. A intervenção cirúrgica é considerada o método de tratamento mais eficiente para esse tipo de neoplasia gástrica (Miettinen et al., 2001). A intervenção cirúrgica também é considerada um importante fator prognóstico, quando completa e com margens de segurança microscopicamente livres do tumor (Anaya et al., 2008).

\section{CONCLUSÃO}

No presente relato, a análise histopatológica foi essencial para a conclusão do diagnóstico de leiomiossarcoma gástrico associado a hérnia de hiato em um cão. Apesar da rara ocorrência dessa neoplasia em regiões estomacais, estudos prospectivos com avaliação histopatológica em casos de tumores gástricos são necessários para confirmar a exata ocorrência dessa neoplasia.

\section{REFERÊNCIAS}

ANAYA, D.A.; LEV, D.C.; POLLOCK, R.E. The role of surgical margin status in retroperitoneal sarcoma. $J$. Surg. Oncol., v.98, p.607-610, 2008.

CHEN, E.; O'CONNELL，F.; FLETCHER， C.D. Dedifferentiated leiomyosarcoma: clinicopathological analysis of 18 cases. Histopathology, v.59, p.11351143,2011

COHEN, M.; POST, G.S.; WRIGHT, J.C. Gastrointestinal leiomyosarcoma in 14 dogs. J. Vet. Intern. Med., v.17, p.107-110, 2003.
DEMETRI, G.D.; ANTONIA, S.; BENJAMIN, R.S. et al. Soft tissue sarcoma. J. Natl. Compr. Cancer Network, v.8, p.630-674, 2010.

FROST, D.; LASOTA, J.; MIETTINEN, M. Gastrointestinal stromal tumors and leiomyomas in the dog: a histopathologic, immunohistochemical, and molecular genetic study of 50 cases. Vet. Pathol., v.40, p.42-54, 2003

HAMAI, Y.; HIHARA, J.; EMI, M. et al. Leiomyosarcoma of the sigmoid colon with multiple liver metastases and gastric cancer: a case report. BMC Gastroenterol., v.12, p.98, 2012.

MCBRIDE, S.M.; RAUT, C.P.; LAPIDUS, M. et al. Locoregional recurrence after preoperative radiation therapy for retroperitoneal sarcoma: adverse impact of multifocal disease and potential implications of dose escalation. Ann. Surg. Oncol., v.20, p.2140-2147, 2013.

MIETTINEN, M.; SARLOMO-RIKALA, M.; SOBIN, L.H. et al. Gastrointestinal stromal tumors, intramural leiomyomas and leiomyosarcomas in the rectum and anus. A clinicopathologic, immunohistochemical and molecular genetic study of 144 cases. Am. J. Surg. Pathol., v.25, p.1121-1133, 2001.

PISTERS, P.W.; LEUNG, D.H.; WOODRUFF, J. et al. Analysis of prognostic factors in 1041 patients with localized soft tissue sarcomas of the extremities. $J$. Clin. Oncol., v.14, p.1679-1689, 1996.

SERRANO, C.; GEORGE, S. Leiomyosarcoma. Hematol. Oncol. Clin. N. Am., v.27, p.957-974, 2013.

SOBRAL, R.A.; DALECK, C.R.; RODASKI, S. et al. Neoplasia do sistema digestório. In: DALECK, C.R.; NARDI, A.B.; RODASKI, S. Oncologia em cães e gatos. São Paulo: ROCA, 2008. p.525-537.

SU, C.H.; CHEN, L.C.; HSIEH, J.S. et al. Organoaxial gastric volvulus caused by incarceration of a gastric stromal tumor in paraesophageal hiatal hernia. Am. Surg., v.24, p.312-313, 2013. 